\title{
Microplastic Contamination of Surface Water-Sourced Tap Water in Hong Kong-A Preliminary Study
}

\author{
Theresa Wing Ling Lam ${ }^{1}$, Hiu Tung Ho ${ }^{1}$, Anson T.H. Ma ${ }^{2}$ and Lincoln Fok ${ }^{1, *}$ \\ 1 Department of Science and Environmental Studies, The Education University of Hong Kong, 10 Lo Ping \\ Road, Tai Po 999077, Hong Kong SAR, China; thwllam@s.eduhk.hk (T.W.L.L.); s1112871@s.eduhk.hk (H.T.H.) \\ 2 Department of Geography and Resource Management, The Chinese University of Hong Kong, \\ Shatin 999077, Hong Kong SAR, China; ansonthma@link.cuhk.edu.hk \\ * Correspondence: lfok@eduhk.hk
}

Received: 13 April 2020; Accepted: 14 May 2020; Published: 17 May 2020

\begin{abstract}
Microplastics have been documented in a wide range of commercially available food products, and the presence of microplastics in tap water has received considerable attention in recent years. Although microplastics in drinking water pose a low concern for human health at current levels of exposure, there is a need to understand the potential pathways for human microplastic exposure. With the application of Rose Bengal staining, microplastics in 110 surface water-sourced tap water samples from urban sources in Hong Kong were qualified and morphologically characterized. A total of 224 items were identified in $86(78.2 \%)$ samples with a mean concentration of $2.181 \pm 0.165 \mathrm{n} \mathrm{L}^{-1}$. Fibrous and smaller $(<1 \mathrm{~mm})$ microplastics predominated in samples, accounting for $97.8 \%$ and $65.1 \%$ of the total microplastic count, respectively. Our results indicated a comparatively low level of microplastic contamination of tap water in Hong Kong. The potential sources of microplastics could be microplastic-polluted water bodies, atmospheric input and mechanical abrasion of plastic equipment during water treatment and distribution.
\end{abstract}

Keywords: microplastics; plastic fibres; tap water; Rose Bengal

\section{Introduction}

Due to their excellent versatility and durability, plastics have come into widespread use, and their global production has increased markedly since the beginning of mass production, from 1.5 million tonnes in 1950 to almost 360 million tonnes in 2018 [1]. Although plastics have benefited our lives in cost and convenience, the indiscriminate disposal of end-of-life plastics poses serious environmental problems, as plastics progressively fragment into smaller pieces once they reach and accumulate in the aquatic environment due to their low biodegradability.

Global concerns have been raised in recent years over the rampant proliferation of plastic debris in the environment, with particular attention paid to microplastics, which are small polymer particles less than $5 \mathrm{~mm}$ in size [2]. Microplastic occurrence has been extensively documented in freshwater and marine environments, such as rivers [3,4], estuaries [5,6], shorelines [7,8] and oceans [9,10]. Given the small size and ubiquity of microplastics, the topic of their effects on global ecosystems has been brought to the forefront. Recently, the introduction of microplastics into the food web via nonselective uptake, unintentional ingestion and ventilation by aquatic organisms was proven by microplastics recovered from the gastrointestinal tracts and/or gills of plankton (e.g., copepods and euphausiids) [11], filter feeders (e.g., bivalves) [12] and fish (e.g., solenette, dragonet and poor cod) [13]. Multiple laboratory studies have further indicated the bottom-up propagation of microplastics across trophic levels and their accumulation in predators [14-16]. Ingestion of microplastics may not only exert various physical impacts, such as external/internal abrasion, intestinal obstruction, reduced energy 
metabolism and reproductive malfunctioning, on aquatic biota [17], but also facilitate the transfer and absorption of chemicals, including hydrophobic organic contaminants (HOCs), from the environment to biota due to the favourable surface-area-to-volume ratio of microplastics [18].

Knowledge of the potential human health impacts associated with the uptake of microplastics is limited at the present stage. Questions have been raised concerning the possible human exposure pathways of microplastics [19]. In addition to commercially available seafoods, microplastics have been observed in table salts [20], beer [21], honey and sugar [22], and even drinking water (i.e., treated tap water and bottled water) $[23,24]$. In 2018, the first study looking into the occurrence of microplastics in tap water reported that more than one-fifth of the tap water samples from 14 countries tested positive for micro-scaled plastic particles, with a vast majority (98.3\%) of microplastics were fibres [25]. Given the presence of microplastics in food, it is possible that humans are exposed to microplastics through ingesting microplastic-contaminated food. However, information related to the microplastic concentration in Hong Kong's tap water remains lacking, exposing the need to understand the presence of microplastics throughout the water supply distribution chain with respect to human exposure and, more broadly, to safeguard drinking water quality.

In Hong Kong, the growth of the urban population and economy has resulted in an increased freshwater demand, with an annual consumption that reached 1010.75 million $\mathrm{m}^{3}$ from 1 April 2018 to 31 March 2019 [26]. Approximately 99.9\% of the Hong Kong population receives tap water from surface water sources, hereafter referred to as raw water. Owing to its freshwater self-insufficiency, Hong Kong derives approximately $70 \%$ of its raw water from the East River (Dongjiang) in Guangdong Province and the rest from impounding reservoirs. There are now 20 water treatment works (WTWs) in Hong Kong with a total capacity for treating 5.31 million $\mathrm{m}^{3}$ of water each day. Raw water is subjected to a five-step treatment process, which comprises coagulation, flocculation, sedimentation, filtration (i.e., gravity and biological filtration) and disinfection, before being delivered to consumers through a designated distribution system (Figure 1).

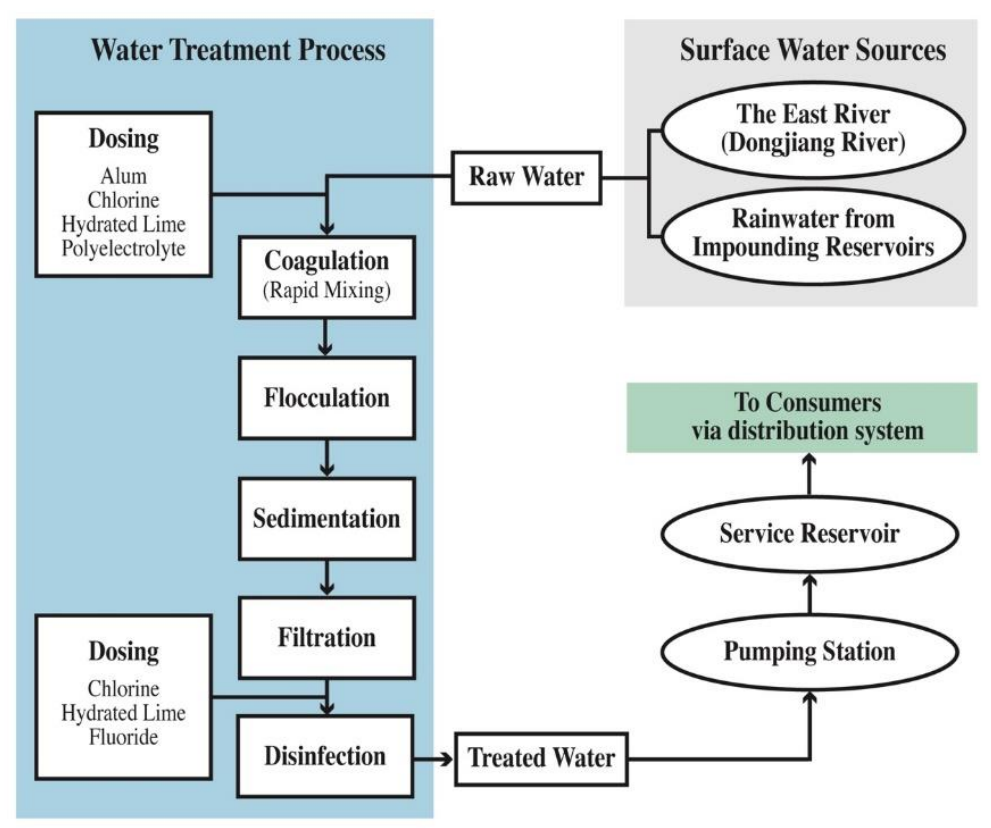

Figure 1. Typical treatment process of raw water in Hong Kong [27].

The purpose of this study was to investigate the presence of microplastics in Hong Kong's tap water. The microplastics in 110 tap water samples collected from urban sources in Hong Kong were quantified and identified. This study aimed (1) to quantify microplastics in Hong Kong's tap water; (2) to classify microplastics by size, shape and colour; and (3) to discuss the potential sources of microplastics in Hong Kong's tap water. 


\section{Methodology}

\subsection{Sampling Sites}

Tap water samples were obtained from 110 urban sites in Hong Kong. The sites included public (i.e., libraries, markets, sports centres, toilets and parks) and private (i.e., shopping centres in public housing estates) properties. Since public and private properties share the same freshwater distribution system with consumer households, obtaining samples from both public and private properties enables the examination of microplastics in Hong Kong's tap water, especially water supplied to households and workplaces that is intended for human consumption. The locations of all sampling sites are specified in Table S1.

\subsection{Sample Collection}

Sampling was conducted from March to April 2018. A total of 110 tap water samples were collected following the method developed by Kosuth, Mason and Wattenberg [25]. Tap water was sampled from a filter-unattached conventional tap after running the tap at a maximum flow for a minimum of $1 \mathrm{~min}$. Each sample was collected by filling a $1 \mathrm{~L}$ high-density polyethylene sample bottle, which was prerinsed three times with filtered deionized water, to the point of overflowing. The bottle was capped tightly and labelled with the sampling location, date and time. All samples were delivered to the laboratory within $24 \mathrm{~h}$ and stored at $4{ }^{\circ} \mathrm{C}$ before analysis.

\subsection{Rose Bengal Staining and Quantification of Microplastics}

In the laboratory, each sample was vacuum filtered over a $2.7 \mu \mathrm{m}$ pore glass microfibre filter (Chmlab Group, Barcelona, Spain) immediately after uncapping the bottle. The wet filter was subjected to Rose Bengal staining according to the method of Liebezeit and Libezeit [21] to aid in the subsequent microplastic identification. A $2 \mathrm{~mL}$ solution of Rose Bengal dye at a concentration of $200 \mathrm{mg} \mathrm{L}^{-1}$ was added to the filter to stain the residual natural organic particles. After $5 \mathrm{~min}$ of impregnation, the dye was filtered off with filtered deionized water, and the filter was oven dried at $60^{\circ} \mathrm{C}$ for $15 \mathrm{~min}$ in a covered glass petri dish.

All dried filters were visually analysed under a stereomicroscope (Olympus, Tokyo, Japan; Model: SZ61) at up to 45X. The nonstained particles with consistent thickness and colour that did not deform when pressed with tweezers were considered plastics [28]. Particle size measurements were carried out to measure the lengths of fibres and the largest diameter of nonfibrous particles using an image software. Images of identified plastic particles were captured and documented before the particles were divided into five size classes: (1) $2.7-149 \mu \mathrm{m}$, (2) $150-499 \mu \mathrm{m}$, (3) $500-999 \mu \mathrm{m}$, (4) 1000-2499 $\mu \mathrm{m}$ and (5) 2500-5000 $\mu \mathrm{m}$. The plastic particles were categorized into four morphotypes: (1) fibre (FB), (2) film (FM), (3) fragment (FM) and (4) pellet (PL) according to the identification criteria outlined in Cheung, Cheung and Fok [29]. The colours of the microplastic particles were also recorded. The whole process was completed within $15 \mathrm{~min}$ for each sample.

\subsection{Statistical Analysis}

The abundance of microplastics in the tap water from each sampling site was calculated by dividing the number of identified microplastics by the total volume of tap water. The values of microplastic abundance were expressed in terms of the number of microplastics per litre of tap water (items $\mathrm{L}^{-1}$, hereafter $\mathrm{L} \mathrm{L}^{-1}$ ). All statistical tests were performed via SPSS software, version 25.0. The number of microplastics in each size, morphotype and colour category was reported using descriptive statistics. To assess the normality of the data set, the Shapiro-Wilk test was adopted, and the results presented a non-normal distribution $(p=0.000)$. In addition, the nonparametric Kruskal-Wallis $H$ test, a multiple-mean comparison, was used to detect the differences in the microplastic abundances. If the test showed significant differences, the Mann-Whitney $U$ test was applied for pairwise comparisons to 
reveal the significantly differing groups. In all cases, the results obtained with $p$ levels $<0.05$ were considered statistically significant.

\subsection{Quality Assurance and Quality Control}

To prevent samples from being contaminated throughout the processing and analysis of samples from external sources (i.e., airborne microplastics), the following measures were implemented: All laboratory personnel were required to wear button-front cotton lab coats and powder-free nitrile-coated gloves when performing any laboratory tasks. To remove any contamination by airborne microplastics, work surfaces were thoroughly cleaned. The deionized water was previously filtered through a $2.7 \mu \mathrm{m}$ pore glass microfibre filter (Chmlab Group, Spain). All glassware and utensils were thoroughly rinsed three times with filtered deionized water and properly kept in a clean metal box before use and covered with aluminium foil when not in use. A procedural blank soaked with filtered deionized water was placed within the laboratory on a daily basis to detect background contamination during the whole experimental period (total hours of exposure: 5.5), and the plastic particles retained on filters were counted using a stereomicroscope (Olympus, Japan; Model: SZ61).

\section{Results}

\subsection{Contamination Control}

The procedural blanks (number of blanks: $n=11$ ) revealed a very low level of microplastic contamination throughout the 5.5-h experimental period, and only two fibres were observed, which represented $<0.01 \%$ of the total count of microplastics in all tap water samples. On average, the microplastic content in the blanks was $0.36 \mathrm{n} \mathrm{hour}^{-1}$ (equivalent to $0.09 \mathrm{n}$ per $15 \mathrm{~min}$ ). With a maximum processing and identification time of $15 \mathrm{~min}$ per sample, the consistent low level or even zero contamination was considered negligible; hence, no blank correction of the quantitative results was made.

\subsection{Abundances and Morphological Characteristics of Microplastics}

A total of 224 microplastics were detected in 86 out of 110 samples (78.2\%) of tap water, and 24 samples $(21.8 \%)$ contained no microplastics (Figure 2). The values of microplastic abundance varied greatly from 0.000 to $8.605 \mathrm{n} \mathrm{L}^{-1}$, with an overall mean ( \pm SEM, standard error of the mean) of $2.181 \pm 0.165 \mathrm{n} \mathrm{L}^{-1}$. The majority of microplastics were fibres (98.7\%; Figure 3a), with only five films (2.2\%; Figure $3 b$ ) found in the samples. Neither pellets nor fragments were observed (Figure $4 a$ ). Microplastics were found in transparent, blue, black and yellow colours. Black microplastics accounted for $42.4 \%$ of the total count, followed by blue $(39.7 \%)$ and transparent $(15.6 \%)$. Few yellowish microplastics $(2.3 \%)$ were detected in the samples (Figure $4 \mathrm{~b})$. The identified microplastics varied greatly in size from 50 to $4830 \mu \mathrm{m}$, with a mean of $949.9 \pm$ SD $913.2 \mu \mathrm{m}$. The size distribution of microplastics displayed a positive skew (skewness $=1.774)$, with a peak at sizes $<1000 \mu \mathrm{m}(65.2 \%$ of the total microplastic count). Microplastics in the size fraction from 150-499 $\mu \mathrm{m}$ were predominant, accounting for $30.8 \%$ of the total count. The relative abundances of particles in the other size categories of $2.7-149 \mu \mathrm{m}, 500-999 \mu \mathrm{m}, 1000-2499 \mu \mathrm{m}$ and $2500-5000 \mu \mathrm{m}$ were $8.9 \%, 25.5 \%, 27.2 \%$ and $7.6 \%$, respectively (Figure 4c). 


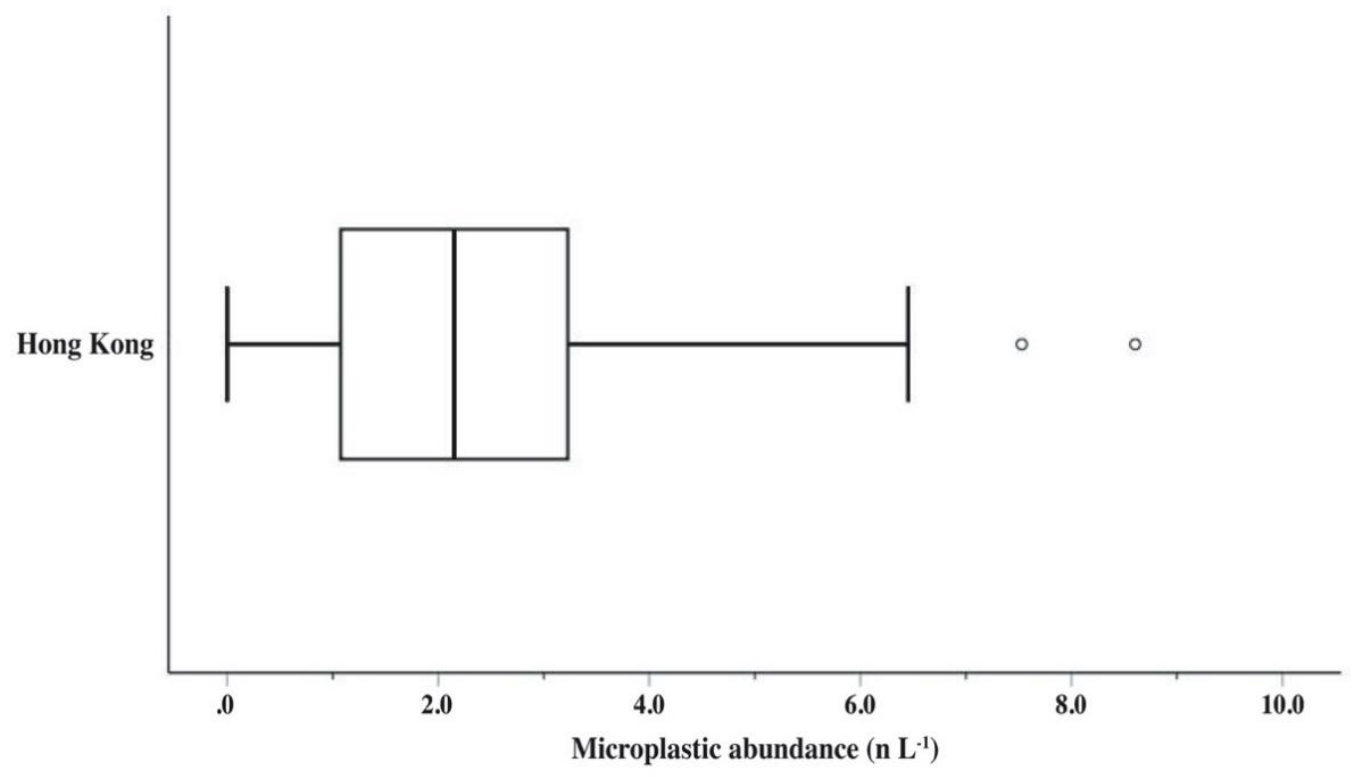

Figure 2. Mean microplastic abundance $\left(\mathrm{n} \mathrm{L}^{-1}\right)$ of Hong Kong tap water samples sourced from surface waters. The box plot shows the median (centreline within the box), 25th and 75th percentiles (box edges), excluding outliers (in circles). Outliers are values of at least 1.5 times the value of the interquartile range (IQR).
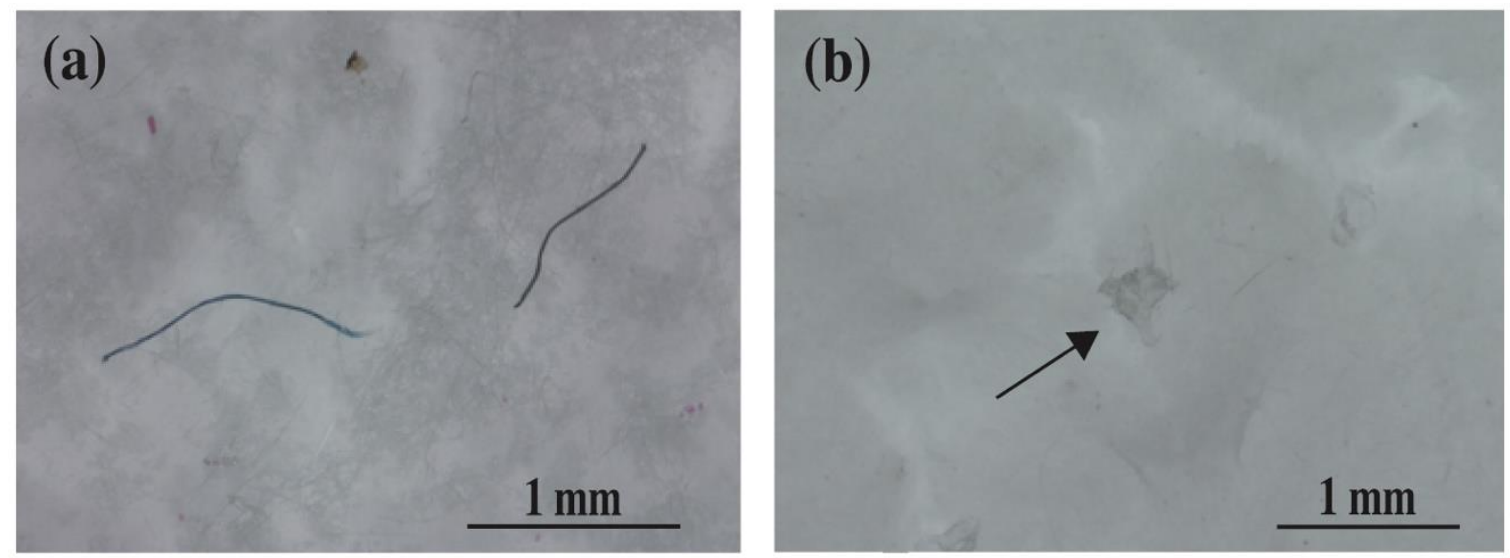

Figure 3. Stereomicroscopic images showing (a) blue (left) and black (right) fibres and (b) a transparent film (black arrow).

(a)

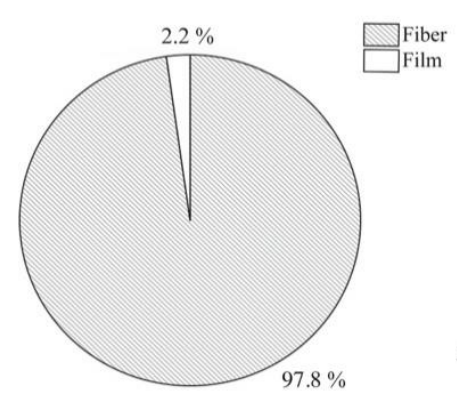

(b)

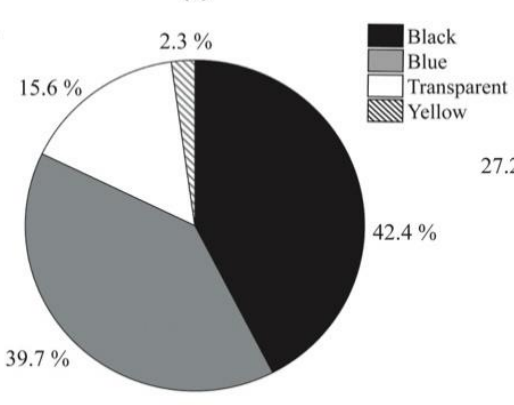

(c)

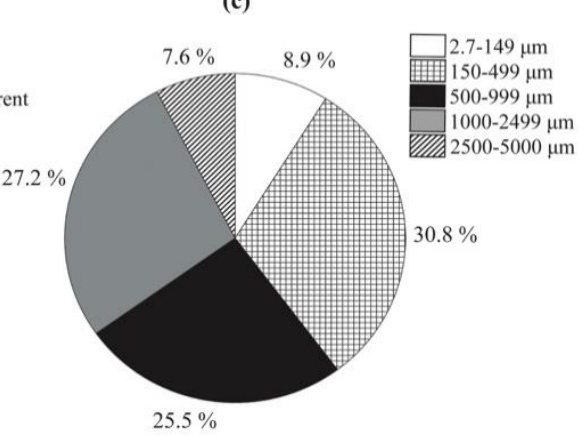

Figure 4. Shape (a), colour (b), and size (c) compositions of microplastics detected in the tap water samples. 


\section{Discussion}

Hong Kong has been recognized as a hotspot of microplastic pollution because of the ubiquitous presence of microplastics in the environment. Microplastics have been detected in beach sediments and coastal surface waters with abundances of $5595 \mathrm{n} \mathrm{m}^{-2}$ and $3.973 \mathrm{n} \mathrm{m}^{-3}$, respectively [30,31]. In addition, microplastic ingestion has been reported in various organisms in Hong Kong, such as captive and wild flathead grey mullet [32], crabs and bivalves [33]. To the best of our knowledge, this is the first report on microplastic pollution in Hong Kong's tap water. Since the first media report released by Orb media [34], several research studies published in the following years have reported the presence of microplastics in tap water, mainly groundwater-sourced, at different concentrations. The abundance of microplastics was found to vary from 0.0007 [35] to $628 \mathrm{n} \mathrm{L}^{-1}$ (the highest microplastic concentration observed among three sampled water treatment plants) [23] for tap water, despite the varied sampling methods and analytical protocols adopted. With an overall concentration of $2.181 \pm 0.165 \mathrm{n} \mathrm{L}^{-1}$, the microplastic contamination level of Hong Kong's tap water was not only comparatively lower than the global average, approximately a 2.5-fold concentration difference [25], but also about 2 orders of magnitude lower than that in Czech Republic (Table 1) [23]. In addition, a markedly higher percentage of samples with lower numbers of microplastics was observed (78.2\%). These findings are in accordance with those reported by Pivokonsky et al. [23] and Kosuth, Mason and Wattenberg [25]. The prevalence of microplastics in tap water means that tap water could be an unneglectable source of microplastics to humans.

Despite the difficulty in determining the exact origin of microplastics in this study, the presence of microplastics in treated water is expected to be linked to the types of source water bodies and various anthropogenic activities in the nearby surroundings, atmospheric input and mechanical abrasion of plastic equipment during water treatment and distribution. In comparison with previous studies of microplastics in groundwater-sourced treated water, higher microplastic abundances tended to be reported for samples sourced from surface waters (Table 1), as surface waters, compared to groundwaters, are susceptible to airborne particulate contamination and less prone to natural filtration of rocks and soils. In Hong Kong, raw water has long been sourced from the East River and local impounding reservoirs. As one of the highly developed areas in China, the East River basin has been undergoing rapid economic development and urbanization. With an increasing population (over 28 million inhabitants in 2010) [36] and expanding production and consumption of plastics, the East River was recently reported to have microplastic pollution with an average abundance of $0.40 \mathrm{n} \mathrm{L}^{-1}$ in surface waters [37], which could represent a potential input pathway of microplastics to raw water. Additionally, there is a high likelihood of microplastics reaching the local reservoirs via atmospheric wet deposition (i.e., precipitation), as a growing body of evidence on the presence of microplastics in urban precipitation samples has indicated. For instance, a previous study in Dongguan, southern China, reported an average daily microplastic concentration of $36 \mathrm{n} \mathrm{m}^{-2}$ in dry and wet atmospheric deposition [38]. Another recent study in the Hamburg Metropolitan Region of Germany also showed a consistent result, with an even higher daily concentration that reached $275 \mathrm{n} \mathrm{m}^{-2}$ [39]. Therefore, it could be possible for airborne microplastics to enter the reservoirs through downward wet deposition fluxes and surface runoff from the catchments. However, although the above two factors seem to explain the major pathways of microplastics to raw water sources, a large-scale investigation on the seasonal variations in microplastic abundance in the source water bodies with a specific focus on the transport behaviour of microplastics, including the residence time and runoff dilution of microplastics, is required to further understand the sources and fates of microplastics in tap water.

Water treatment is critically important, as it poses a barrier to microplastic entry into drinking water. Unfortunately, although current water treatment practices primarily aim to remove impurities, the removal is selective and ineffective for filtering out all microplastics. As demonstrated by Pivokonsky et al. [23], a two-stage sedimentation-sand filtration technique for water purification was only capable of removing an average of $81 \%$ of the microplastics from surface water sources. Since interstage monitoring was not conducted in the present study, it was unable to confirm whether 
the presence of microplastics in water is attributable to the incomplete removal of plastic particles or the release of smaller microplastics following mechanical abrasion during treatment and distribution; for example, rapid mixing in coagulation may degrade stressed polymer particles under high shearing forces [19], and the abrasion of plastic-coated or plastic-lined water pipes and tanks could also result in microplastic fragmentation [35]. Thus, only very limited conclusions can be drawn at the current stage, and further research is needed to address this question.

The detected microplastics were mostly tiny in size and nearly invisible to the naked eye. According to the World Health Organization [19], microplastics of a size greater than $150 \mu \mathrm{m}$ tend not to be absorbed in vivo due to their insolubility and are believed to be eliminated through direct excretion. In addition, the oral intake of smaller microplastics appears to be limited at the exposure levels recorded in the literature. Based on the actual amounts and sizes of microplastics reported by Pivokonsky et al. [23] and Kosuth, Mason and Wattenberg [25] (Table 1), the estimated intake of microplastics from tap water was $2 \mu \mathrm{g} \mathrm{day}^{-1}$ or $0.03 \mu \mathrm{g} \mathrm{kg}{ }^{-1}$ body weight per day [19]. Considering that an average local microplastic abundance is at most only half of the values reported in the above two studies, the daily intake of microplastics via Hong Kong tap water is likely to be at a very low level.

Microplastic research on drinking water is still in its infancy. Since no research has been carried out to investigate the human health impacts of microplastics with particle sizes below $150 \mu \mathrm{m}$, no firm conclusion can be reached with limited data on whether smaller microplastics cause harm to human health. In addition, due to a lack of standardized methods for microplastic analysis, studies are often incomparable and unable to provide meaningful results, as the approaches adopted by studies for sample collection, microplastic quantification and identification have greatly varied [40]. Since the presence of microplastics smaller than $1 \mu \mathrm{m}$ has been reported in treated water samples from the Czech Republic [23], the use of $2.7 \mu \mathrm{m}$ pore filter papers in this study could hinder accurate detection and quantification of smaller microplastics, which means that the abundance and size distribution of microplastics in the tap water in Hong Kong might have been underestimated. Despite the urgency of establishing an accurate and standardized method for paving the way towards efficient detection and analysis of micro- and nano-plastics in drinking water, this remains a significant challenge, as the reliability across published studies was not sufficient [41]. At the current stage, much attention should be paid to determining how to maintain a low-loss and contamination-free sample processing procedure to obtain robust and reproducible results. Certain measures, including rinsing laboratory equipment three times with filtered deionized water, working in a laboratory with clean air devices and performing replicated controls, are recommended. 
Table 1. Comparison of reported microplastic abundances in treated water samples sourced from both ground and surface waters. The data of this study are highlighted in bold.

\begin{tabular}{|c|c|c|c|c|c|c|c|c|}
\hline Study Area & Water Source & Sample Size & Sampling Method & Filter Pore Size $(\mu \mathrm{m})$ & $\begin{array}{l}\text { Mean Microplastic } \\
\text { Abundance (n L-1) }\end{array}$ & Predominant Particle Size $(\mu \mathrm{m})$ & $\begin{array}{l}\text { Predominant } \\
\text { Shape Type }\end{array}$ & Reference \\
\hline Germany & Groundwater & 15 & $\begin{array}{l}\text { Sampling at the outlet of a } \\
\text { drinking water treatment plant, at } \\
\text { a water metre and at a water tap }\end{array}$ & 0.2 & 0.0007 & In the range of $50-150$ & Fragments & Mintenig et al. [35] \\
\hline Demark & Groundwater & 17 & Sampling at a water tap & 0.2 & 0.58 & Not specified & Fibres $(82 \%)$ & Strand et al. [42] \\
\hline Czech Republic & Surface water ${ }^{a}$ & 36 & $\begin{array}{l}\text { Sampling at the outlet of a } \\
\text { drinking water treatment plant }\end{array}$ & 0.2 & $\begin{array}{l}443 \text { (WTP1) } \\
338 \text { (WTP2) } \\
628 \text { (WTP3) }\end{array}$ & In the range of $1-10$ & Fragments & Pivokonsky et al. [23] \\
\hline Global & Not specified & 159 & Sampling at a water tap & 2.5 & 5.45 & $\begin{array}{l}\text { Not specified, fibre lengths ranged } \\
\text { from } 100-5000\end{array}$ & Fibres $(98.3 \%)$ & $\begin{array}{l}\text { Kosuth, Mason and } \\
\text { Wattenberg [25] }\end{array}$ \\
\hline Hong Kong & Surface water & 110 & $\begin{array}{l}\text { Sampling at a filter-unattached } \\
\text { water tap }\end{array}$ & 2.7 & 2.181 & In the range of $150-499(30.8 \%)$ & Fibres $(97.8 \%)$ & This study \\
\hline
\end{tabular}

Remarks: ${ }^{a}$ Treated water samples were obtained directly from the outlets of three water treatment plants. 


\section{Conclusions}

The abundance and morphological characteristics of microplastics in Hong Kong's tap water have been presented in the present study. The average concentration of microplastics in the tap water ranged from 0.000 to $8.605 \mathrm{n} \mathrm{L}^{-1}$, with an overall mean of $2.181 \pm 0.165 \mathrm{n} \mathrm{L}^{-1}$, indicating a minor contamination of the tap water compared with the results available in published studies. It is believed that the current levels of direct microplastic exposure via drinking water are unlikely to cause major health problems, but the potential risks to human health should not be neglected. Further research is needed to determine the routes by which microplastics enter the water treatment and distribution system and to establish standard methods for the sampling and detection of micro- and nano-plastics.

Supplementary Materials: The following are available online at http://www.mdpi.com/2076-3417/10/10/3463/s1, Table S1: Locations of tap water sampling sites in Hong Kong.

Author Contributions: Conceptualization: H.T.H. and L.F.; methodology: T.W.L.L., H.T.H. and L.F.; formal analysis: T.W.L.L. and H.T.H.; writing—original draft preparation: T.W.L.L. and A.T.H.M.: writing-review and editing: L.F. All authors have read and agreed to the published version of the manuscript.

Funding: This research was partially funded by the General Research Fund, Research Grants Council, Government of Hong Kong SAR, grant number 18300618.

Acknowledgments: The authors would like to thank the funding support from the Research Grants Council, Government of Hong Kong SAR.

Conflicts of Interest: The authors declare no conflicts of interest.

\section{References}

1. PlasticsEurope. Plastics-the Facts 2019: An Analysis of European Plastics Production, Demand and Waste Data; Plastics Europe Market Research Group: Brussels, Belgium, 2019.

2. Arthur, C.; Baker, J.; Bamford, H. Workshop Summary. In Proceedings of the International Research Workshop on the Occurrence, Effects, and Fate of Microplastic Marine Debris, Tacoma, WA, USA, 9-11 September 2008.

3. Mani, T.; Hauk, A.; Walter, U.; Burkhardt-Holm, P. Microplastics profile along the Rhine River. Sci. Rep. 2015, 5, 1-7. [CrossRef] [PubMed]

4. Lin, L.; Zuo, L.-Z.; Peng, J.-P.; Cai, L.-Q.; Fok, L.; Yan, Y.; Li, H.-X.; Xu, X.-R. Occurrence and distribution of microplastics in an urban river: A case study in the Pearl River along Guangzhou City, China. Sci. Total Environ. 2018, 644, 375-381. [CrossRef] [PubMed]

5. Zhao, S.; Zhu, L.; Li, D. Microplastic in three urban estuaries, China. Environ. Pollut. 2015, 206, 597-604. [CrossRef] [PubMed]

6. Yonkos, L.T.; Friedel, E.A.; Perez-Reyes, A.C.; Ghosal, S.; Arthur, C.D. Microplastics in four estuarine rivers in the Chesapeake Bay, USA. Environ. Sci. Technol. 2014, 48, 14195-14202. [CrossRef] [PubMed]

7. Karthik, R.; Robin, R.; Purvaja, R.; Ganguly, D.; Anandavelu, I.; Raghuraman, R.; Hariharan, G.; Ramakrishna, A.; Ramesh, R. Microplastics along the beaches of southeast coast of India. Sci. Total Environ. 2018, 645, 1388-1399. [CrossRef]

8. Lee, J.; Lee, J.S.; Jang, Y.C.; Hong, S.Y.; Shim, W.J.; Song, Y.K.; Hong, S.H.; Jang, M.; Han, G.M.; Kang, D. Distribution and size relationships of plastic marine debris on beaches in South Korea. Arch. Environ. Contam. Toxicol. 2015, 69, 288-298. [CrossRef]

9. Avio, C.G.; Gorbi, S.; Regoli, F. Plastics and microplastics in the oceans: From emerging pollutants to emerged threat. Mar. Environ. Res. 2017, 128, 2-11. [CrossRef]

10. Isobe, A.; Uchida, K.; Tokai, T.; Iwasaki, S. East Asian seas: A hot spot of pelagic microplastics. Mar. Pollut. Bull. 2015, 101, 618-623. [CrossRef]

11. Desforges, J.-P.W.; Galbraith, M.; Ross, P.S. Ingestion of microplastics by zooplankton in the Northeast Pacific Ocean. Arch. Environ. Contam. Toxicol. 2015, 69, 320-330. [CrossRef]

12. Van Cauwenberghe, L.; Janssen, C.R. Microplastics in bivalves cultured for human consumption. Environ. Pollut. 2014, 193, 65-70. [CrossRef]

13. Lusher, A.; Mchugh, M.; Thompson, R. Occurrence of microplastics in the gastrointestinal tract of pelagic and demersal fish from the English Channel. Mar. Pollut. Bull. 2013, 67, 94-99. [CrossRef] [PubMed] 
14. Farrell, P.; Nelson, K. Trophic level transfer of microplastic: Mytilus edulis (L.) to Carcinus maenas (L.). Environ. Pollut. 2013, 177, 1-3. [CrossRef] [PubMed]

15. Santana, M.; Moreira, F.; Turra, A. Trophic transference of microplastics under a low exposure scenario: Insights on the likelihood of particle cascading along marine food-webs. Mar. Pollut. Bull. 2017, 121, 154-159. [CrossRef] [PubMed]

16. Setälä, O.; Fleming-Lehtinen, V.; Lehtiniemi, M. Ingestion and transfer of microplastics in the planktonic food web. Environ. Pollut. 2014, 185, 77-83. [CrossRef] [PubMed]

17. Wright, S.L.; Thompson, R.C.; Galloway, T.S. The physical impacts of microplastics on marine organisms: A review. Environ. Pollut. 2013, 178, 483-492. [CrossRef]

18. Cole, M.; Lindeque, P.; Halsband, C.; Galloway, T.S. Microplastics as contaminants in the marine environment: A review. Mar. Pollut. Bull. 2011, 62, 2588-2597. [CrossRef]

19. World Health Organization. Microplastics in Drinking-Water; WHO: Geneva, Switzerland, 2019.

20. Yang, D.; Shi, H.; Li, L.; Li, J.; Jabeen, K.; Kolandhasamy, P. Microplastic pollution in table salts from China. Environ. Sci. Technol. 2015, 49, 13622-13627. [CrossRef]

21. Liebezeit, G.; Liebezeit, E. Synthetic particles as contaminants in German beers. Food Addit. Contam. Part A 2014, 31, 1574-1578. [CrossRef]

22. Liebezeit, G.; Liebezeit, E. Non-pollen particulates in honey and sugar. Food Addit. Contam. Part A 2013, 30, 2136-2140. [CrossRef]

23. Pivokonsky, M.; Cermakova, L.; Novotna, K.; Peer, P.; Cajthaml, T.; Janda, V. Occurrence of microplastics in raw and treated drinking water. Sci. Total Environ. 2018, 643, 1644-1651. [CrossRef]

24. Mason, S.A.; Welch, V.G.; Neratko, J. Synthetic polymer contamination in bottled water. Front. Chem. 2018, 6, 1-11. [CrossRef] [PubMed]

25. Kosuth, M.; Mason, S.A.; Wattenberg, E.V. Anthropogenic contamination of tap water, beer, and sea salt. PLoS ONE 2018, 13, 1-18. [CrossRef] [PubMed]

26. Water Supplies Department of HKSAR. Hong Kong: The Facts-Water Supplies. Available online: https://www.wsd.gov.hk/en/publications-and-statistics/pr-publications/the-facts/index.html (accessed on 30 November 2019).

27. Water Supplies Department of HKSAR Quality Water. Water: Learn E Conserve, Teaching Kit for Liberal Studies; Water Supplies Department: Hong Kong, China, 2011.

28. Bellas, J.; Martínez-Armental, J.; Martínez-Cámara, A.; Besada, V.; Martínez-Gómez, C. Ingestion of microplastics by demersal fish from the Spanish Atlantic and Mediterranean Coasts. Mar. Pollut. Bull. 2016, 109, 55-60. [CrossRef] [PubMed]

29. Cheung, P.K.; Cheung LT, O.; Fok, L. Seasonal variation in the abundance of marine plastic debris in the estuary of a subtropical macro-scale drainage basin in South China. Sci. Total Environ. 2016, 562, 658-665. [CrossRef]

30. Fok, L.; Cheung, P.K. Hong Kong at the Pearl River Estuary: A hotspot of microplastic pollution. Mar. Pollut. Bull. 2015, 99, 112-118. [CrossRef]

31. Cheung, P.K.; Fok, L.; Hung, P.L.; Cheung, L.T. Spatio-temporal comparison of neustonic microplastic density in Hong Kong waters under the influence of the Pearl River Estuary. Sci. Total Environ. 2018, 628, 731-739. [CrossRef]

32. Cheung LT, O.; Lui, C.Y.; Fok, L. Microplastic contamination of wild and captive flathead grey mullet (mugil cephalus). Int. J. Environ. Res. Public Health 2018, 15, 597. [CrossRef]

33. Xu, X.; Wong, C.; Tam, N.F.; Lo, H.-S.; Cheung, S.-G. Microplastics in invertebrates on soft shores in Hong Kong: Influence of habitat, taxa and feeding mode. Sci. Total Environ. 2020, 715, 136999. [CrossRef]

34. Orb. Water: Tap, Bottled \& Microplastics. Available online: https://orbmedia.org/blog/water-tap-bottledmicroplastics (accessed on 2 April 2020).

35. Mintenig, S.; Löder, M.; Primpke, S.; Gerdts, G. Low numbers of microplastics detected in drinking water from ground water sources. Sci. Total Environ. 2019, 648, 631-635. [CrossRef]

36. Ding, J.; Jiang, Y.; Liu, Q.; Hou, Z.; Liao, J.; Fu, L.; Peng, Q. Influences of the land use pattern on water quality in low-order streams of the Dongjiang River basin, China: A multi-scale analysis. Sci. Total Environ. 2016, 551, 205-216. [CrossRef]

37. Fan, Y.; Zheng, K.; Zhu, Z.; Chen, G.; Peng, X. Distribution, sedimentary record, and persistence of microplastics in the Pearl River catchment, China. Environ. Pollut. 2019, 251, 862-870. [CrossRef] [PubMed] 
38. Cai, L.; Wang, J.; Peng, J.; Tan, Z.; Zhan, Z.; Tan, X.; Chen, Q. Characteristic of microplastics in the atmospheric fallout from Dongguan city, China: Preliminary research and first evidence. Environ. Sci. Pollut. Res. 2017, 24, 24928-24935. [CrossRef] [PubMed]

39. Klein, M.; Fischer, E.K. Microplastic abundance in atmospheric deposition within the Metropolitan area of Hamburg, Germany. Sci. Total Environ. 2019, 685, 96-103. [CrossRef] [PubMed]

40. Hidalgo-Ruz, V.; Gutow, L.; Thompson, R.C.; Thiel, M. Microplastics in the marine environment: A review of the methods used for identification and quantification. Environ. Sci. Technol. 2012, 46, 3060-3075. [CrossRef]

41. Koelmans, A.A.; Nor NH, M.; Hermsen, E.; Kooi, M.; Mintenig, S.M.; De France, J. Microplastics in freshwaters and drinking water: Critical review and assessment of data quality. Water Res. 2019, 155, 410-422. [CrossRef]

42. Strand, J.; Feld, L.; Murphy, F.; Mackevica, A.; Hartmann, N.B. Analysis of Microplastic Particles in Danish Drinking Water; Aarhus University, DCE-Danish Centre for Environment and Energy: Aarhus, Denmark, 2018.

(C) 2020 by the authors. Licensee MDPI, Basel, Switzerland. This article is an open access article distributed under the terms and conditions of the Creative Commons Attribution (CC BY) license (http://creativecommons.org/licenses/by/4.0/). 